\title{
Formation of Assessment Competence of Future Teachers of Mathematics
}

\author{
Irina Shmigirilova ${ }^{1},{ }^{*}$ Lydia Shestakova ${ }^{2}$ \\ ${ }^{1}$ M. Kozybayev North Kazakhstan University, Kazakhstan \\ ${ }^{2}$ Perm State University, Russia \\ *Email: irinankzu@mail.ru
}

\begin{abstract}
The article deals with the problem of formation of assessment competence of future teachers of mathematics. The purpose of the study: to identify the conditions of university education that determine the effectiveness of the formation of the assessment competence of future teachers of mathematics. The authors apply theoretical analysis and generalization of scientific research on the formation of competencies; generalization of advanced pedagogical experience; integrative approach in identifying the components of the assessment competence of future teachers of mathematics. In the process of expert discussion, the conditions for the formation of assessment competence of future teachers of mathematics are identified and then generalized with the help of the integrative approach. The pedagogical experiment confirmed the positive influence of the selected conditions on the formation of students' assessment competence.
\end{abstract}

Keywords: Assessment competence, Mathematics teacher training, University education, Integrative approach.

\section{INTRODUCTION}

The concept of "competence" in the literature is interpreted in different ways. V.S. Chouhan and S. Srivastava [1] make a review of foreign literature on the definition of the concept itself, tracing the history of the formation and modeling of competencies that are in demand in the modern economy. The authors emphasize that the effectiveness of any organization depends on the assessment and development of the competence of employees. Based on the analyzed studies, five elements are identified in the structure of competence (knowledge, skills, values and attitudes, traits - physical characteristics, motives).

In this study, the authors consider competence as a complex of knowledge, skills and readiness to use them to solve professional problems. The assessment competence of a mathematics teacher determines the teacher's theoretical and practical readiness and ability to perform effective professionally-oriented assessment activities.
The interest towards the problem of formation of assessment competence in professional communities of scientists and teachers around the world is due to the reform processes in the educational systems of different countries, which also affect approaches to assessing students' educational achievements. The literature reveals the features of assessment at the levels of general and professional education, approaches to the formation of students' assessment skills. However, the problem of determining the conditions for the formation of assessment competence of future mathematics teachers is not sufficiently presented in the researches. The integrative approach was not implemented in the study of this problem. The purpose of the presented research is to identify the conditions for the formation of assessment competence of future mathematics teachers.

\section{LITERATURE REVIEW}

The system of general education is focused on the formation of students' competencies, universal learning activities (ULA), which imposes a number of 
requirements for the readiness of a mathematics teacher to form ULA and evaluate learning outcomes. Therefore, the preparation of a student-teacher for assessment activities is one of the tasks of professional education. There are publications in the literature devoted to various aspects of the issue under consideration. E.V. Ivashchenko, T.M. Struchaeva [2] investigate the issues of preparing primary school teachers to assess the educational achievements of schoolchildren, considering such readiness as a necessary element of professional development of students. M.A. Panyushkina [3] studies the problem of formation of evaluative-qualimetric competencies of the future bachelor of pedagogical education through its inclusion in the solution of practiceoriented evaluative-qualimetric problems. The problem of the influence of self-assessment and mutual assessment on the activity of students-teachers is considered in the publication 1.G. Shestakova, Y.A. Kharitonova, T.V. Rikhter [4]. Questions of formation of assessment actions of undergraduates are studied in the works of A.M. Nazhmiddinov [5] (in the aspect of managerial competence), H.A. Alizhanov, M.O. Omarova [6] (as an element of project competence of a teacher).

The need to highlight the components of assessment competence required a detailed analysis of the assessment activity of a mathematics teacher. The assessment activity itself has a complex character. In the aspect of the development of the assessment competence of the future teacher, it is important to note that the task of evaluating the results of students is added to the need to form their knowledge, skills and abilities to control their own educational activities and implement selfassessment. Foreign researchers [7, 8, etc.] along with the category "assessment competence" use the term "assessment literacy", defining it also in the aspect of structural and content features of assessment activities.

An integrative approach was used to identify the components of the assessment competence of a mathematics teacher. The questions of an integrative approach in education are covered by Russian and foreign authors. Let's focus on a number of works related to the topic of the article. In the work of V.N. Klepikov, it is noted that integration is "a mechanism, technology, method, reception, result or state, depending on specific educational goals, circumstances and conditions" [9, p.3]. A similar conclusion is made in the works of others [10, 11 , etc.]. The authors, relying on the analysis of literature, note that the integrative approach in pedagogical literature is characterized in different ways. P.J.T. White, M.K. Heidemann, and J.J. Smith write about the implementation of the integrative approach in natural science education [12].

On the basis of an integrative approach, the assessment activity of a mathematics teacher was analyzed and three main directions were identified in which it is implemented. First, the teacher needs to evaluate the learning outcomes of students, analyze them and implement corrective actions. Secondly, students need to develop the ability to control and verify the performed mathematical calculations or problem solving. In other words, students need to purposefully form techniques for self-assessment of their own educational results, which, among other things, can be attributed to the possession of universal educational activities. Third, the teacher must be able to carry out self-assessment of their own professional level, achievements and problems in the implementation of professional activities, and set tasks for professional self-improvement in order to plan their career growth and obtain a higher qualification category (level). The directions described by us were included as components in the assessment competence of the future mathematics teacher:

AC-1 (assessment competence-1) - the ability to selfevaluate with the formulation of professional selfimprovement tasks;

AC-2 - the ability to evaluate each other;

AC-3 - the ability to evaluate the learning outcomes of students;

AC-4 - the ability to form students' methods of selfassessment of learning outcomes (personal, metasubject and subject).

It should be noted that in the structure of assessment competence, we did not single out the value component separately, considering it to be the same for all pedagogical (professional) competencies.

The formation and development of assessment competence, as well as any complex neoplasm in the personality structure, depends on many factors, which in turn are provided through the creation of special pedagogical conditions. N.V. Ippolitova and V.S. Sterkhova [13] note that conditions, being an element of an integral pedagogical system, determine the totality of opportunities inherent in the educational environment, affecting the personal and procedural components of this system in the direction of ensuring its effective functioning and development.

Thus, an integrative approach to identifying the conditions that determine the effectiveness of the formation of assessment competence in future mathematics teachers indicates the need to reflect in their totality the content-activity and technological capabilities of the educational environment.

\section{RESEARCH METHODOLOGY}

On the basis of theoretical analysis and generalization of the scientific researches on the formation of competencies, the components of assessment competence were identified, it was established that the 
structure of the set of pedagogical conditions aimed at the formation of the considered competence should reflect the possibilities of the educational environment.

The set of conditions for the formation of the assessment competence of future mathematics teachers was determined on the basis of an expert survey with their subsequent structuring. The experts were 15 teachers of mathematics, selected on the recommendation of the school administration and who passed a preliminary interview. Each of the experts in any form described the conditions, the implementation of which in the process of training future teachers of mathematics will contribute to the effective formation of their assessment competence.

The work on evaluating of the effectiveness of the selected conditions for the formation of students' assessment competence was carried out on the basis of the Faculty of Mathematics and Natural Sciences of the North Kazakhstan University named after M. Kozybayev (participated: 20 students of the educational program "Mathematics" - the experimental group and 21 students of the educational program "Informatics" - control group) and the Solikamsk State Pedagogical Institute (branch) of the Perm State National Research University (participated: 12 students enrolled in the educational program of the direction "Pedagogical Education" (direction "Mathematics and Economics") experimental group and 12 students of the same direction (direction "Primary Education" - control group) in 20172020.

To check the objectivity of the results of the experimental training, the chi-square criterion was applied.

\section{THE RESULTS OF THE STUDY}

The organization of the educational process of training a future mathematics teacher in the experimental group was carried out in accordance with the conditions for the formation of students' assessment competence, the totality of which was the result of structuring a set of conditions determined by experts.

The first group of conditions determines the need to provide theoretical training of students on the problem of educational assessment. One of the main directions of this group of conditions was to include in the educational program a content block that provides students with knowledge about the assessment process, methods, techniques and tools for evaluating the educational results of schoolchildren, as well as methods and techniques of self-assessment and mutual assessment.

The second group of conditions is aimed at purposeful inclusion of students in assessment activities through the following types of work:
- the integration in the process of mastering disciplines (modules), practices of teacher's assessment, self-assessment and mutual assessment of students;

- use of self-assessment and mutual assessment in extracurricular and scientific work with students.

In particular, as part of the implementation of this group of conditions, the technology of the educational reflexive portfolio was tested [14].

The third group of conditions is focused on the practical preparation of students for the assessment of the learning outcomes of schoolchildren. To ensure these conditions in the assignment for student teaching practice there were included the following activities: allocation of the learning outcomes of the subject (highlighting preventive actions for typical errors and difficulties of students); selection (adaptation) diagnostic tools; diagnostics; analysis of results planning of corrective actions (for the admitted errors and the obtained results); corrective action and analysis; use of techniques of selfassessment and mutual assessment in working with children.

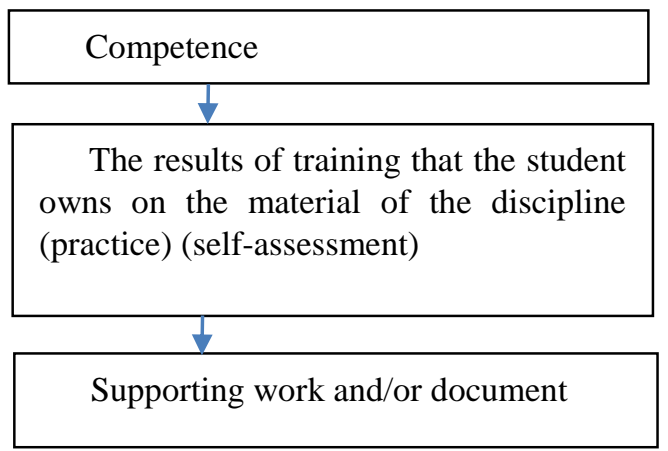

Figure 1 The structure of the electronic portfolio (documents).

The fourth group of conditions indicates the need for the use of information technologies in the educational process, in particular, the use of an electronic portfolio to confirm (demonstrate) the possession of competencies, structured according to the formed competencies. An electronic portfolio is created throughout the entire learning process and is used at the stage of evaluating students' proficiency in competencies at the final (state final) certification. Working with an electronic portfolio, its gradual filling, contributes to ensuring the conscious need of students for self-change on the basis of professional and personal self-assessment. The structure of the electronic portfolio is presented in figure 1.

To determine the level of formation of assessment competence, together with the teachers of the two abovementioned universities, an assessment category was developed, in which level indicators for the component of assessment competence were allocated. The maximum 
Table 1. Distribution of students in the control and experimental groups according to the levels of development of assessment competence

\begin{tabular}{|l|c|c|c|c|}
\hline \multirow{2}{*}{$\begin{array}{l}\text { Levels of development of } \\
\text { assessment competence }\end{array}$} & \multicolumn{3}{|c|}{ Distribution by level } \\
\cline { 2 - 5 } & \multicolumn{2}{|c|}{ The experimental group } & \multicolumn{2}{c|}{ The control group } \\
\cline { 2 - 5 } & $\begin{array}{c}\text { start of the } \\
\text { experiment }\end{array}$ & $\begin{array}{c}\text { start of the } \\
\text { experiment } \\
\text { experiment }\end{array}$ & $\begin{array}{c}\text { end of the } \\
\text { experiment }\end{array}$ \\
\hline Initial & 19 & 0 & 18 & 0 \\
\hline Intermediate & 11 & 2 & 13 & 15 \\
\hline Basic & 0 & 9 & 0 & 5 \\
\hline Advanced & 0 & 19 & 0 & 11 \\
\hline
\end{tabular}

assessment competence for the sum of points for all components can be estimated at 12 points. The levels of assessment competence formation were established: 10 12 points - advanced level; 7-9 points - basic level; 4-6 points - intermediate level; below 4 points - initial level.

The distribution of students by the assessment competence levels is shown in the following table 1 . The verification of the objectivity of the results of the experiment was carried out with the help of the Pearson chi-square test.

Prior to the experiment, the calculation of Tobserve gives the value of Tobserve $=0.1613$, while Tcrit. $=$ 11.345 with a significance level $\rho=0.01$. That is Tobserve $<$ Tcrit., the differences in the level of development of the assessment competence of students of the control and experimental groups before the experiment are random.

After calculating the Tobserve for the data at the end of the experiment, we get the value Tobserve $=11.9032$. We have Tobserve > Tcrit., it can be concluded that the compliance with the identified conditions in the process of university training of future teachers contributes to the formation and development of their assessment competence.

\section{CONCLUSION}

On the basis of an integrative approach, an analysis of the assessment activity of a mathematics teacher is carried out, its components are highlighted: the ability to self-evaluate with the formulation of professional selfimprovement tasks; the ability to mutually evaluate; the ability to evaluate the results of teaching students; the ability to form methods of self-assessment of learning results (personal, metasubject and subject).

There are identified groups of conditions for formation of assessment competency of the future mathematics teachers: enabling meaningful unit of assessment, the self-assessment, peer testing and the methods of their conduct; purposeful inclusion of students in assessment activities; practical training of students in the assessment of learning outcomes of pupils; the use of electronic portfolio, structured according to the competencies in the assessment of knowledge of students competences on the final (state final) certification.

During the study it was confirmed that the conditions of formation of future mathematics teachers' assessment competency are effective, as the results of formation of assessment competence in the experimental group are higher than in the control.

During the training, it was noticed that the students of the experimental group approached the tasks of selfassessment and mutual assessment, as well as to evaluating students, more consciously. It was also noted that the electronic portfolios presented by students, structured by competencies, greatly facilitate the decision on the level of development of each component of the assessment competence.

As a continuation of the work, it is possible to transfer the described experience to other areas and training profiles. An interesting question is the transfer of the results obtained to the formation of the results of teaching students.

\section{AUTHORS' CONTRIBUTION}

I. Shmigirilova - the analysis of the literature; treatment of empirical data, modification of the text of the article.

L. Shestakova - the development of the idea, research methodology, preparation of the preliminary version of the article.

\section{ACKNOWLEDGMENTS}

This research has been funded by the Science Committee of the Ministry of Education and Science of the Republic of Kazakhstan (Grant No. A08956027 "Innovative approaches to the assessment of educational achievements of students in terms of updating the content of mathematical education"). 


\section{REFERENCES}

[1] V.S. Chouhan, S. Srivastava, Understanding Competencies and Competency Modeling - A Literature Survey, IOSR Journal of Business and Management $16 \quad$ (2014) 14-22. DOI: https://doi.org/10.9790/487X-16111422

[2] E.V. Ivashchenko, T.M. Struchaeva, Model of preparation of the future primary school teacher for the assessment of educational achievements of schoolchildren, Bulletin of the Tomsk State Pedagogical University 1(103) (2011) 97-102. Retrieved from: https://www.elibrary.ru/item.asp?id=15578134 (In Russ.)

[3] M.A. Panyushkina, Evaluation and qualimetric competencies of the future teacher as a pedagogical concept, Scientific and methodological electronic journal "Concept" 4 (2019) 69-77. Retrieved from: http://e-koncept.ru/2019/191031.htm (In Russ.).

[4] L.G. Shestakova, Y.A. Kharitonova, T.V. Rikhter. Assessing activity of pedagogical college students as a study activation tool, Indian Journal of Science and Technology 9(21) (2016) 1-8. DOI: https://doi.org/10.17485/ijst/2016/v9i21/95221

[5] A.M. Nazhmiddinov, Modeling of managerial competence of the head of an educational institution, Azimuth of scientific research: pedagogy and psychology 2(23) (2018) 177-179. Retrieved from: https://www.elibrary.ru/item.asp?id=35326152 (In Russ.).

[6] Kh.A. Alizhanova, M.O. Omarova, Improvement of professional training of a modern teacher, Culture. Spirituality. Society 8 (2013) 168-172. Retrieved from:

https://www.elibrary.ru/item.asp?id=20927430 (In Russ.).

[7] C.De Luca Preparing teachers for the age of accountability: Toward a framework for assessment education, Action in Teacher Education 34(5/6) (2012) 576-591. DOI: https://doi.org/10.1080/01626620.2012.730347

[8] C. Wyatt-Smith, C. Alexander, D. Fishburn, McMahon P. Standards of practice to standards of evidence: developing assessment capable teachers, Assessment in Education: Principles, Policy \& Practice 24(2) (2017) 250-270. DOI: https://doi.org/10.1080/0969594X.2016.1228603

[9] V.N. Klepikov, Integration Processes in Modern education, School Technologies 5 (2014) 3-14. Retrieved https://www.elibrary.ru/item.asp?id=22266513 (In Russ.).

[10] G.Ya Grevtseva, M.V. Tsiulina, E.A. Bolodurina, M.I. Bannikov, Integrative approach in the educational process of higher education, Modern problems of science and education 5 (2017) Retrieved from: http://scienceeducation.ru/ru/article/view?id=26857

[11] M. Jovanović, V. Kovcic, Contemporary society challenges of integrative teaching, Sinteze, (2017) 39-71. DOI: https://doi.org/10.5937/sinteze6-13812

[12] P.J. T White, M.K. Heidemann, J.J.A. Smith. New Integrative Approach to Evolution Education, BioScience 63(7) (2013) 586-594. DOI: https://doi.org/10.1525/bio.2013.63.7.11

[13] N.V. Ippolitova, N.A. Sterkhova, Analysis of the concept of "pedagogical conditions": essence, classification, Generaland Professional Education 1 (2012) 8-14. Retrieved from: http://genproedu.com/paper/2012-01/full_008014.pdf (In Russ.).

[14] I.B Shmigirilova, A.S. Rvanova, A.A. Tadgigitov, Portfolio as the assessment tool in training of future teacher of mathematics, Vestnik KazNPU named after Abaya, series "Pedagogical sciences" 3(67) (2020) 83-87. Retrieved from: http://sp.kaznpu.kz/docs/jurnal file/file202011050 11254.pdf (In Russ.). 